Article

\title{
Synthesis of Pd-M@HCS(M = Co, Ni, Cu) Bimetallic Catalysts and Their Catalytic Performance for Direct Synthesis of $\mathrm{H}_{2} \mathrm{O}_{2}$
}

\author{
Yaodan Wang ${ }^{1,2}$, Hongyan Pan ${ }^{1,2,3, *}$, Qian Lin ${ }^{1,2, *}$, Yongyong Shi ${ }^{1,2}$ and Jiesong Zhang ${ }^{1,2}$ \\ 1 Department of Chemical Engineering, School of Chemistry and Chemical Engineering, Guizhou University, \\ Guiyang 550025, China; wangyaodan1994@163.com (Y.W.); shiyongyong2006@163.com (Y.S.); \\ zjs248369@163.com (J.Z.) \\ 2 Guizhou Key Laboratory for Green Chemical and Clean Energy Technology, Guiyang 550025, China \\ 3 State Key Laboratory of Efficient Utilization for Low Grade Phosphate Rock and Its Associated Resources, \\ Guiyang 550014, China \\ * Correspondence: cepanhongyan@163.com (H.P.); celinqian@126.com (Q.L.)
}

Received: 24 February 2020; Accepted: 3 March 2020; Published: 6 March 2020

\begin{abstract}
Hydrogen peroxide $\left(\mathrm{H}_{2} \mathrm{O}_{2}\right)$, as a clean and green oxidant, is widely used in many fields. The direct synthesis of $\mathrm{H}_{2} \mathrm{O}_{2}$ (DSHP) from $\mathrm{H}_{2}$ and $\mathrm{O}_{2}$ has attracted most research interest because it relates to a facile, environmentally friendly, and economic process. Yolk-shell Pd-M@HCS (hollow carbon sphere) ( $\mathrm{M}=\mathrm{Co}, \mathrm{Ni}, \mathrm{Cu})$ nanocatalysts, in which the bimetal nanoparticle is the core and porous carbon works as the shell layer, are reported in this work. It was found that catalytic activities were enhanced because of the introduced M metals. Additionally, the different mass ratios of Pd to $\mathrm{Co}(\mathrm{mPd} / \mathrm{mCo})$ were further investigated to improve the catalytic performance for the DSHP. When $\mathrm{mPd} / \mathrm{mCo}$ was 4.4, the prepared Pd-Co@HCS-(4.4) catalyst, with an average Pd nanoparticle size of $7.30 \mathrm{~nm}$, provided the highest $\mathrm{H}_{2} \mathrm{O}_{2}$ selectivity of $87 \%$ and $\mathrm{H}_{2} \mathrm{O}_{2}$ productivity of $1996 \mathrm{mmolg}_{\mathrm{Pd}}{ }^{-1} \cdot \mathrm{h}^{-1}$, which were increased by $24 \%$ and $253 \%$, respectively, compared to Pd@HCS.
\end{abstract}

Keywords: direct synthesis of hydrogen peroxide; Pd-based catalyst; yolk-shell structure

\section{Introduction}

Hydrogen peroxide $\left(\mathrm{H}_{2} \mathrm{O}_{2}\right)$, which has been diversely used for producing a wide range of products [1-6], is considered a green and clean raw material due to its highly atomic utilization and environmentally friendly properties. The direct synthesis of $\mathrm{H}_{2} \mathrm{O}_{2}$ (DSHP) from hydrogen and oxygen is believed a promising method since $\mathrm{H}_{2} \mathrm{O}$ is the only by-product during the producing process [7-9]. However, the side reaction in the DSHP process, like the formation of $\mathrm{H}_{2} \mathrm{O}$, is more easily thermodynamic and thus results in a low selectivity of synthesis of $\mathrm{H}_{2} \mathrm{O}_{2}$ and a poor stability in general. To improve this process, palladium (Pd)-based catalysts as highly efficient active components have been extensively studied [10]. Moreover, bimetallic nanocatalyst have shown higher catalytic activity product selectivity and stability, thus attracting the most research interest. Recently, Pd-based bimetallic materials that were incorporated with $3 \mathrm{~d}$ structure transition metals (such as $\mathrm{Fe}, \mathrm{Co}$, and $\mathrm{Ni}$ ) were found to present excellent selectivity, stability and activity in various organic reactions [11]. Additionally, incorporating cheap transition metals can reduce the amount of the noble metal while maintaining decent catalytic activity. It was reported that a higher $\mathrm{H}_{2} \mathrm{O}_{2}$ yield was achieved by using $\mathrm{Au}-\mathrm{Pd} / \mathrm{Al}_{2} \mathrm{O}_{3}$ compared to $\mathrm{Au} / \mathrm{Al}_{2} \mathrm{O}_{3}$ and $\mathrm{Pd} / \mathrm{Al}_{2} \mathrm{O}_{3}$ in the DSHP process [12]. Simon et al. [13] proved that $\mathrm{Pd}-\mathrm{M} / \mathrm{SiO}_{2}(\mathrm{M}=\mathrm{Mi}, \mathrm{Zn}, \mathrm{Ga}$, In and $\mathrm{Co})$ showed good catalytic activity in DSHP. However, However, the performance of such supported catalysts is still not desirable due to the migration, shedding, and agglomeration of the active component Pd. Recently, Violeta Paunovic et al. [14] reported 
that an Au-Pd bimetallic catalyst in a wall-coated microchannel was developed for DSHP. The catalyst that is constructed on a microchannel wall can avoid migration, resulting in higher stability, selectivity, and productivity. However, the active sites might be covered by the microchannels and thus reduce the utilization of the catalyst. Inspired by these studies, this work developed bimetallic Pd-M $(\mathrm{M}=\mathrm{Co}$, $\mathrm{Ni}$ and $\mathrm{Cu}$ ) catalysts with yolk-shell structures where the active component $\mathrm{Pd}-\mathrm{M}$ was used as the core and a hollow carbon sphere was used as the shell (Pd-M@HCS). This yolk-shell structure can prevent the migration of the catalyst while enhancing the exposure of the active components of Pd-M to the reaction system. As a result, both the catalytic activity and atom utilization of the catalyst can be improved. This work provides a solution to the challenge that most of the active sites in conventional coated core-shell catalysts are covered with shell materials.

The Pd-M@HCS samples were synthesized by a reverse microemulsion method, where polyethylene glycol monocetyl ether (Brij56) was used as surfactant and cyclohexane and a Pd-M bimetallic nanosphere solution were used as the oil phase solvent and the aqueous phase, respectively. The formed water-in-oil reversed micelle was reduced by $\mathrm{NaBH}_{4}$ to form Pd-M@HCS. Phenolic $\operatorname{Resin}(\mathrm{RF})$ nanospheres $[15,16]$ and $\mathrm{SiO}_{2}$ nanospheres [17] were synthesized by the polymerization of resorcinol, formaldehyde, and tetraethyl orthosilicate (TEOS), respectively. The TEM showed that the Pd was coated by the Co to form hollow nanospheres of Pd-Co@HCS. Thus, a suitable ratio of Pd to Co meant a better Pd-coated structure and led to a better catalytic performance. This work then further investigated the effect of different mass ratios of $\mathrm{Pd}$ to $\mathrm{Co}, \mathrm{m}_{\mathrm{Pd}} / \mathrm{m}_{\mathrm{Co}}$, on the DSHP performance.

\section{Results and Discussion}

\subsection{Characterization of Pd@HCS and Pd-M@HCS}

\subsubsection{Morphology of Pd@HCS and Pd-M@HCS}

Figure 1 shows the morphology, histograms of the size distribution and element components of the prepared catalysts Pd@HCS and Pd-M@HCS $(\mathrm{M}=\mathrm{Co}, \mathrm{Ni}, \mathrm{Cu})$. The EDS patterns, shown in Figure $1 \mathrm{a}^{\prime \prime \prime}-\mathrm{d}^{\prime \prime \prime}$, indicate that $\mathrm{C}, \mathrm{O}, \mathrm{Si}, \mathrm{Pd}$ and $\mathrm{Cu}$ existed in all prepared samples. $\mathrm{Pd}, \mathrm{C}$ and $\mathrm{O}$ were the main components of the catalysts. A small amount of $\mathrm{Si}$ was detected due to the unremoved $\mathrm{SiO}_{2}$ during the etching process. The existing $\mathrm{Cu}$ was mainly from the copper grid for the TEM sampling. Additionally, the Co and Ni existing in the Pd-M@HCS $(\mathrm{M}=\mathrm{Co}, \mathrm{Ni})$ indicated that the obtained catalysts were modified by $\mathrm{Co}$ and $\mathrm{Ni}$. It should be noted that the intensity of $\mathrm{Cu}$ in Figure $1 \mathrm{~d}^{\prime \prime \prime}$ is stronger than others, implying that the $\mathrm{Cu}$ was successfully incorporated into Pd-Cu@HCS.

As shown in Figure 1a-d, the TEM images revealed that the Pd and Pd-M nanoparticles were encapsulated with a carbon sphere, forming a multicore-shell structure where the metals were the cores and porous carbon was the shell layer. Additionally, the average particle size of the Pd nanoparticles in Pd Pd@HCS among the prepared catalysts was the biggest with intensive agglomeration, as illustrated in Figure $1 a^{\prime}-d^{\prime}$. During the synthesis process, the cationic surfactant CTAB formed spherical micelles in which the hydrophobic hydrocarbon chains oriented inward, whereas the cationic hydrophilic groups directed outward. Because of electrostatic attraction, the $\left[\mathrm{PdCl}_{4}\right]^{2-}(\mathrm{pH}=10)$ ions were mainly located on the surface of the spherical micelles, and $\mathrm{M}^{2+}$ ions were adsorbed on the $\left[\mathrm{PdCl}_{4}\right]^{2}$ ions. When CTAB was removed, the structure of the catalysts was assumed to be that of a hollow nanosphere. Nevertheless, the TEM images indicated that the composite contained several core crystals. The multi-core structure might have been formed during the pyrolysis process when the single crystal nanosphere was dispersed at a high temperature. Moreover, the free $\mathrm{Pd}$ atoms might have been deposited on the nanospheres when they were reduced by $\mathrm{NaBH}_{4}$ and afterwards formed a multi-core structure as well. The formation of Pd-M@HCS is illustrated in Scheme 1. Scheme 1 shows the synthetic route for the yolk-shell nanocatalyst Pd@HCS. The core of the catalyst was Pd nanoparticles that were synthesized by a reverse microemulsion method, and the shell was a porous carbon sphere with a uniform thickness that was prepared by the calcination of a polymer resin layer, which was formed by the self-assembly of a cationic surfactant, CTAB, resorcinol, and RF. The preparation of the catalyst 
Pd@HCS was divided into four steps. First is the synthesis of Pd nanoparticles, which was done with surfactant Brij56, co-surfactant n-octanol, the oil phase solvent cyclohexane, and an aqueous solution of Pd-M by a reverse microemulsion method. When the Pd-M solution was added dropwise into the oil-phase containing surfactant, it interacted more easily with the hydrophilic head of the surfactant due to the principle of dissolution in a similar material structure; then, it was surrounded by the oil phase solvent cyclohexane, and, in the end, a large number of water-in-oil nanodroplets were produced. These droplets served as nanoreactors that provided a unique environment for the nucleation and growth of the Pd nanoparticles. After the dynamic balance of the reverse microemulsion system was attained, the reductant $\mathrm{NaBH} 4$ was added to this solution to reduce precursor Pd-M to Pd-M nanoparticles [18].
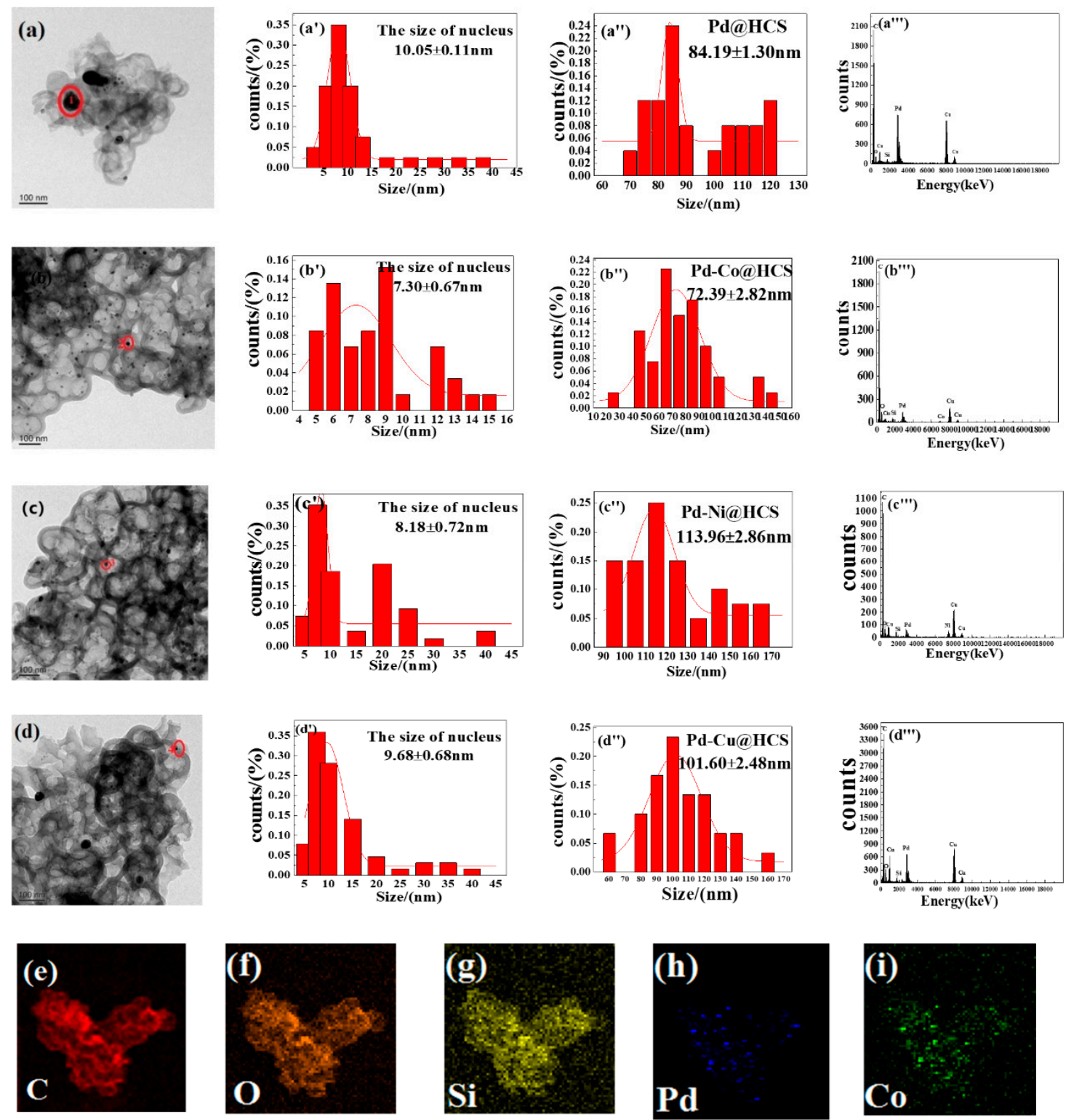

Figure 1. TEM images, histograms of the size distribution and EDS patterns of the catalysts: $\left(\mathbf{a}, \mathbf{a}^{\prime}, \mathbf{a}^{\prime \prime}, \mathbf{a}^{\prime \prime \prime}\right)$ Pd@HCS (hollow carbon sphere), (b, $\left., \mathbf{b}^{\prime}, \mathbf{b}^{\prime \prime}, \mathbf{b}^{\prime \prime \prime}\right)$ Pd-Co@HCS, (c, $\left.\mathbf{c}^{\prime}, \mathbf{c}^{\prime \prime}, \mathbf{c}^{\prime \prime \prime}\right)$ Pd-Ni@HCS and $\left(\mathbf{d}, \mathbf{d}^{\prime}, \mathbf{d}^{\prime \prime}, \mathbf{d}^{\prime \prime \prime}\right)$ Pd-Cu@HCS. (e-i) are EDS mapping analysis of Pd-Co@HCS. 


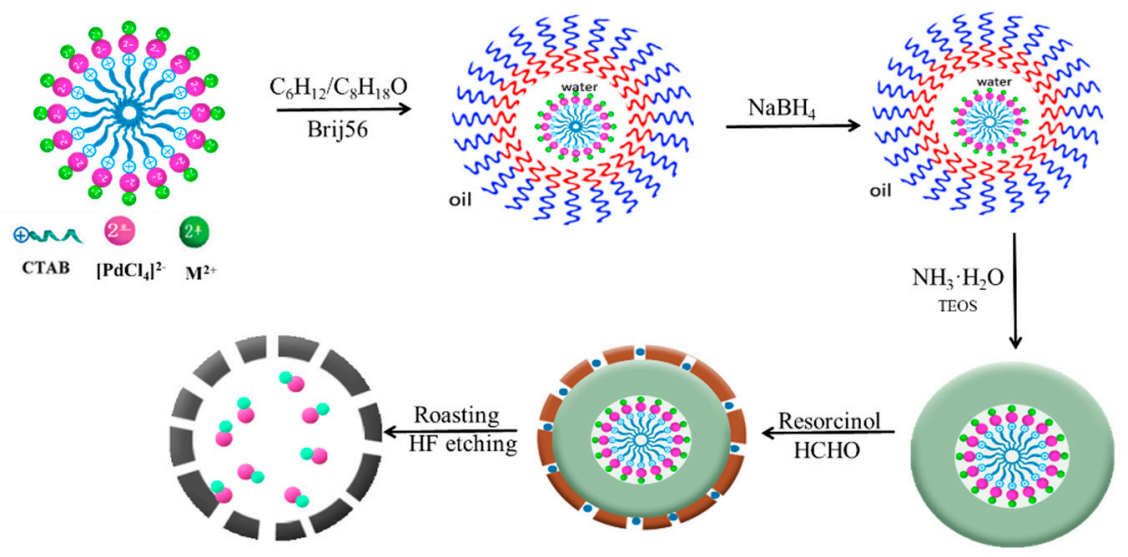

Scheme 1. Synthetic route of Pd-M@HCS.

The growth of the Pd nanoparticles was inhibited when M components were introduced, resulting in a reduced particle size of metallic nanoparticles, as shown in Figure 1a'-d'. Additionally, after the removal of surfactant, the bimetallic crystal was nucleated, and the nanospheres were dispersed, thereby restricting the agglomeration of nanoparticles and further reducing the particle size.

Compared to Pd-Ni@HCS and Pd-Cu@HCS, Pd-Co@HCS presented the smallest average nanoparticle size $(7.30 \pm 0.67 \mathrm{~nm})$, which was suggested to be more conducive to the DSHP reaction since the smaller size of the metal core could expose more active sites and thus enhance the dissociation of hydrogen bonds to generate $\mathrm{H}_{2} \mathrm{O}_{2}$. The smaller size that existed in Pd-Co@HCS might have been caused by the smaller particle size of $\mathrm{Co}$ than that of $\mathrm{Ni}$ and $\mathrm{Cu}$.

Figure 1e-i displays the EDS mapping of the Pd-Co@HCS, which illustrates that C, O, Si, Pd and Co were included in the prepared catalysts. This was consistent with the added elements during the preparation process. Moreover, due to the different reduction potentials of Co (II) and Pd (II), the metal that existed in the catalyst was a Pd-Co bimetal, not alloy. Their location was demonstrated in Figure $1 \mathrm{~h}, \mathrm{i}$.

\subsubsection{XRD Pattern of Pd@HCS and Pd-M@HCS}

The XRD patterns of Pd@HCS and Pd-M@HCS, shown in Figure 2, demonstrate that the characteristic diffraction peaks of Pd, corresponding to Pd (1 111$),(200)$ and (2 20$)$, exited in the four

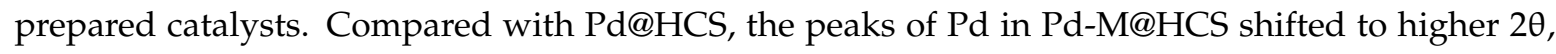
which clearly confirmed that the Pd-M bimetal catalysts [19] were obtained. The broad diffraction peak located at $2 \theta=25^{\circ}$ was attributed to amorphous carbon. In addition to the diffraction peaks of Pd existed in Pd-Co@HCS, the Co characteristic peak was not observed. It is assumed that the particle size of Co was too small to be detected by XRD. Furthermore, it can be suggested that the $\mathrm{Pd}-\mathrm{M}$ bimetallic nanoparticles will react with $\mathrm{SiO}_{2}$ to form a Pd-Si composite material [20] when carbonized at $600{ }^{\circ} \mathrm{C}$. In this work, the diffraction peaks of $\mathrm{Pd}_{2} \mathrm{Si}$ were observed in Pd-Ni@HCS and Pd-Cu@HCS, and these were located at $2 \theta=41.3^{\circ}$ and $48.3^{\circ}$ for Pd-Ni@HCS and $2 \theta=41.8^{\circ}, 42.6^{\circ}$ and $48.7^{\circ}$ for Pd-Cu@HCS. Additionally, the existing Si in Pd-M@HCS helped to separate the bimetallic particles and thus limited the agglomeration of the core nanoparticles. As a result, multi-cores were generated. Additionally, the crystal sizes of Pd nanoparticles on Pd@HCS, Pd-Co@HCS, Pd-Ni@HCS and Pd-Cu@HCS that were calculated by the Scherrer formula were 13.55, 7.29, 8.40, and $8.52 \mathrm{~nm}$, respectively, which were approximately consistent with the results from the TEM (Figure 1). The reduced size of the nanoparticles indicated that the agglomeration of $\mathrm{Pd}$ could be effectively reduced by incorporating the component $\mathrm{M}(\mathrm{Co}, \mathrm{Ni}$ and $\mathrm{Cu})$. 


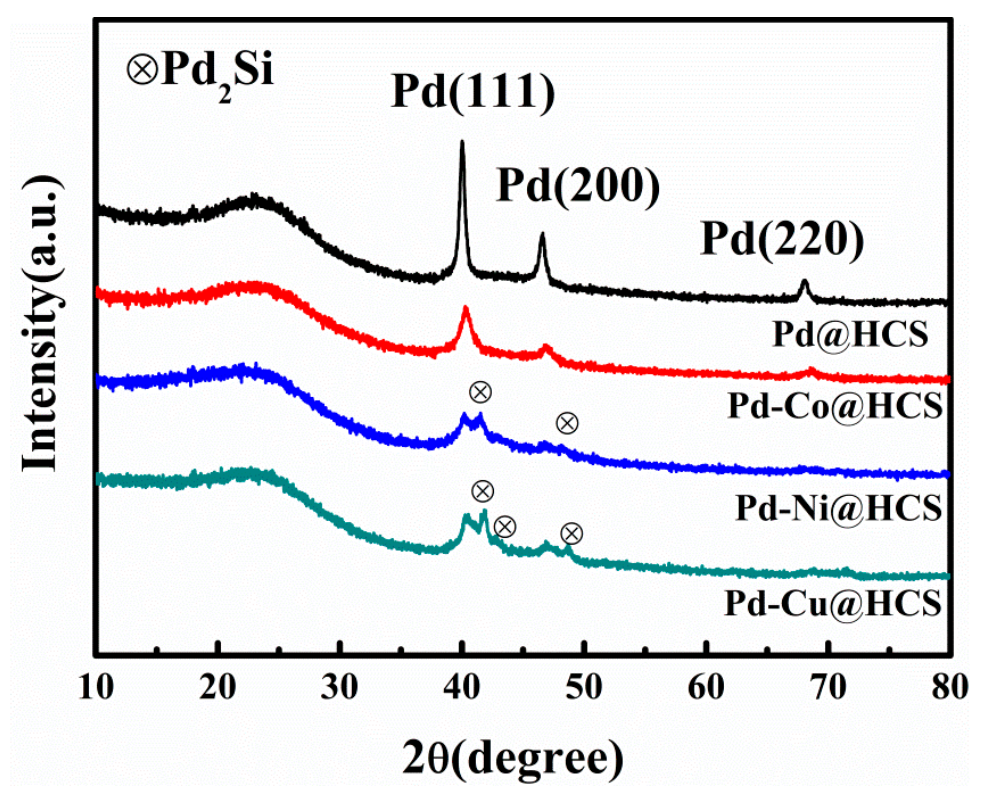

Figure 2. XRD patterns of Pd@HCS and Pd-M@HCS.

\subsection{3. $\mathrm{N}_{2}$ Adsorption-Desorption of Pd@HCS and Pd-M@HCS}

Figure $3 \mathrm{a}, \mathrm{b}$ display the $\mathrm{N}_{2}$ adsorption-desorption isotherms and pore size distribution (PSD) of the four catalysts, respectively. As shown in Figure 3a, all the four synthesized catalysts belonged a typical type II isotherm adsorption curve. The monolayer adsorption occurring at low relative pressure range $\left(\mathrm{P} / \mathrm{P}_{0}<0.01\right)$ with a small amount of adsorbed $\mathrm{N}_{2}$ indicated that all four catalysts contained micropores. The $\mathrm{N}_{2}$ adsorption amount gradually increased with the increase of $\mathrm{P} / \mathrm{P}_{0}$, but it increased sharply when $\mathrm{P} / \mathrm{P}_{0}>0.9$, indicating that all the four catalysts contained micropores and macropores. Moreover, a hysteresis loop appeared around $\mathrm{P} / \mathrm{P}_{0}$ from 0.4 to 0.9 , which is a typical phenomenon of capillary agglomeration that occurs when $\mathrm{N}_{2}$ is adsorbed simultaneously on mesopores and macropores. This reveals that the pores of the all the four catalysts were mainly composed of mesopores but contained some micropores and macropores. The different areas of the hysteresis loop of the four catalysts indicated that the mesoporous contents in the catalysts were different. For instance, the area of Pd@HCS was significantly larger than that of the other three catalysts, implying that it had the largest mesopore contents over others. As shown in Figure $3 b$, the pore size distribution of the four prepared catalysts was mainly located at 5-100 nm, which suggests that they had large numbers of mesopores and macropores with small amounts of micropores. The pores less than $2 \mathrm{~nm}$ were the pore channels of the porous carbon shell. The textural properties and Pd loading of the prepared samples is summarized in Table 1. It should be noted that the average micropore size of the porous carbon layer was larger than the kinetic diameters of the reactant molecules $\left(\mathrm{H}_{2}\right.$ and $\left.\mathrm{O}_{2}\right)$, product molecule $\left(\mathrm{H}_{2} \mathrm{O}_{2}\right)$ and by-product $\left(\mathrm{H}_{2} \mathrm{O}\right)$, which facilitated mass transfer and diffusion when the catalysis reaction proceeded.

As listed in Table 1 , the surface area $\left(\mathrm{S}_{\mathrm{BET}},\right)$ and average pore volume $\left(\mathrm{V}_{\mathrm{mic}}\right)$ were increased when $\mathrm{M}$ components were added. Pd-Co@HCS had the largest $\mathrm{S}_{\mathrm{BET}}$ among them, which as beneficial for the diffusion of the reactants and products, resulting in an enhanced catalytic activity. The greater $\mathrm{S}_{\mathrm{BET}}$ was also confirmed by TEM since the Pd-Co had a smaller nanoparticle size and better dispersion. On the other hand, the average shell pore size, $\mathrm{D}_{\text {pore, }}$ of Pd-Co@HCS was smaller than that of Pd-Ni@HCS and Pd-Cu@HCS, indicating that the Pd-Co nanoparticles could be easily encapsulated by the shell carbon and could consequently avoid agglomerating. Therefore, Pd-Co@HCS was assumed to be more efficient for the synthesis of $\mathrm{H}_{2} \mathrm{O}_{2}$. The Pd loading in the synthesized catalysts was around $4 \mathrm{wt} . \%$, as detected by ICP (Inductively Coupled Plasma) characterization; see Table 1. 

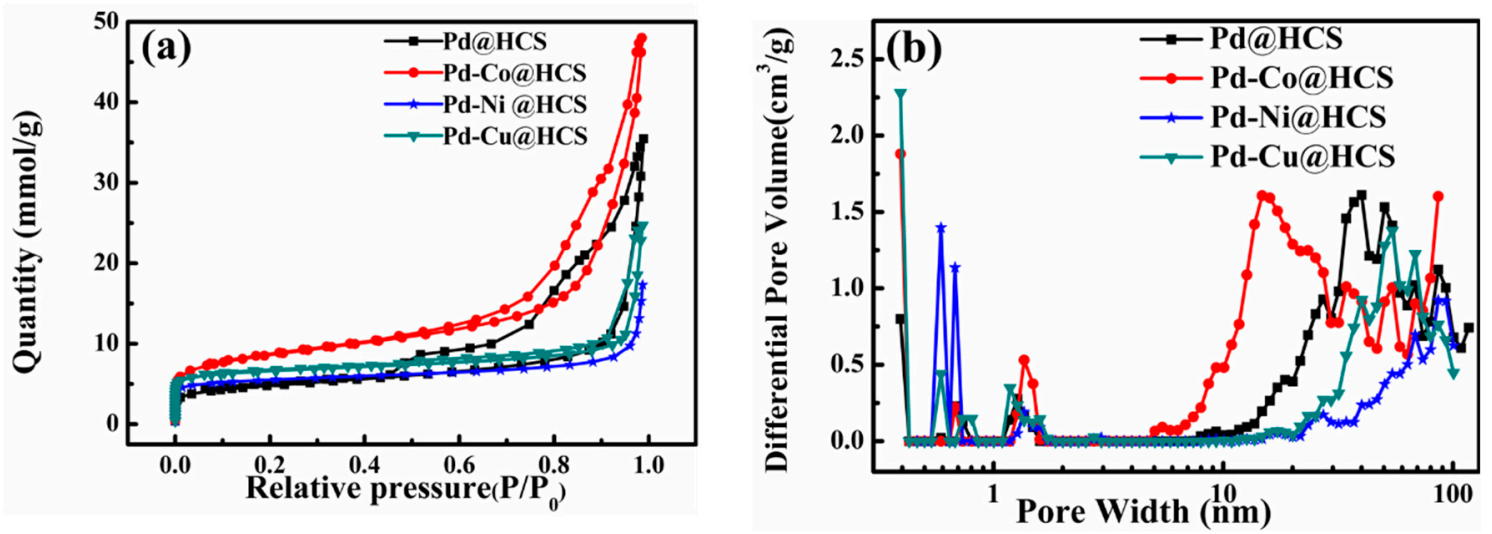

Figure 3. $\mathrm{N}_{2}$ adsorption-desorption of Pd@HCS and Pd-M@HCS. (a) Isotherm adsorption line; (b) pore size distribution.

Table 1. Textural properties and Pd loading of the prepared samples.

\begin{tabular}{|c|c|c|c|c|}
\hline Catalysts & $\mathrm{S}_{\mathrm{BET}}{ }^{\mathrm{a}}\left(\mathrm{m}^{2} / \mathrm{g}\right)$ & $\mathrm{V}_{\text {mic }}{ }^{\mathrm{b}}\left(\mathrm{cm}^{3} / \mathrm{g}\right)$ & $D_{\text {pore }}{ }^{c}(\mathrm{~nm})$ & Pd Loading ${ }^{d}(w t \%)$ \\
\hline Pd@HCS & 379.01 & 0.09 & 15.83 & 4.05 \\
\hline Pd-Co@HCS & 683.36 & 0.16 & 8.78 & 4.05 \\
\hline Pd-Ni@HCS & 434.52 & 0.15 & 13.81 & 4.03 \\
\hline Pd-Cu@HCS & 523.38 & 0.19 & 11.46 & 4.02 \\
\hline
\end{tabular}

${ }^{\text {a }} \mathrm{S}_{\text {BET }}$ was calculated by the BET equation; ${ }^{\mathrm{b}} \mathrm{V}_{\text {mic }}$ was calculated by the BJH equation; ${ }^{\mathrm{c}} \mathrm{D}_{\text {pore }}$ was calculated by the density functional theory (DFT) model; ${ }^{\mathrm{d}} \mathrm{Pd}$ loading was calculated by ICP characterization.

\subsubsection{Activity Test of Pd@HCS and Pd-M@HCS for DSHP}

Figure 4 shows the catalytic performances of the catalysts Pd@HCS and Pd-M@HCS for the direct synthesis of $\mathrm{H}_{2} \mathrm{O}_{2}$ from $\mathrm{H}_{2}$ and $\mathrm{O}_{2}$. Among them, Pd-Co@HCS provided the best $\mathrm{H}_{2}$ conversion, $\mathrm{H}_{2} \mathrm{O}_{2}$ yield, $\mathrm{H}_{2} \mathrm{O}_{2}$ selectivity, and $\mathrm{H}_{2} \mathrm{O}_{2}$ productivity, which were $33 \%, 29 \%, 87 \%$ and $1996 \mathrm{mmolg}_{\mathrm{Pd}}{ }^{-1} \mathrm{~h}^{-1}$, respectively. Compared with Pd@HCS $\left(10 \%, 7 \%, 70 \%\right.$ and $\left.565 \mathrm{mmolg}_{\mathrm{Pd}}{ }^{-1} \mathrm{~h}^{-1}\right)$, the $\mathrm{H}_{2}$ conversion, $\mathrm{H}_{2} \mathrm{O}_{2}$ yield, $\mathrm{H}_{2} \mathrm{O}_{2}$ selectivity, and $\mathrm{H}_{2} \mathrm{O}_{2}$ productivity were increased by $230 \%, 314 \%, 24 \%$, and $253 \%$, respectively. As discussed before, the larger number of high-energy active sites that were exposed on $\mathrm{Pd}-\mathrm{Co}$ than Pd due to the smaller core size was more conducive to the DSHP reaction. Meanwhile, Pd-Co@HCS had a larger specific surface area and pore volume, which could provide stronger adsorption of $\mathrm{H}_{2}$ and $\mathrm{O}_{2}$, thereby improving the catalytic selectivity. Additionally, the $\mathrm{H}_{2}$ conversion was improved because the highly dispersed Pd-Co surface provided a higher concentration of active hydrogen by diffusing hydrogen from Pd to Co. In addition, the enhanced catalytic performances of Pd-Co@HCS was also attributed to synergistic effect between Pd and Co, as well as the bi-site effect where both metals played specific role with respect to the reactants [21]. Since Pd-Co@HCS presented an attractive catalytic performance for the DSHP, the different mass ratios of Pd to Co were investigated further.

\subsection{Characterization of Pd-Co@HCS-(X)}

\subsubsection{XRD pattern of Pd-Co@HCS-(X)}

Figure 5 shows the XRD patterns of Pd-Co@HCS-(1), Pd-Co@HCS-(2.8), Pd-Co@HCS-(4.4) and

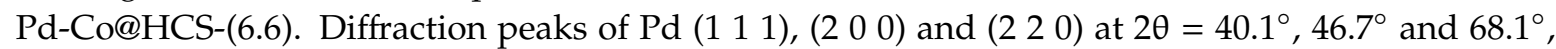
respectively, were observed. The abroad perk located at $2 \theta=25^{\circ}$ was amorphous carbon. Except for the characteristic diffraction peaks of Pd and carbon, no new diffraction peak was detected for the four catalysts. It was assumed that the particle size of Co was very small and thereby lower than the detection limitation of XRD. The crystal sizes of Pd, calculated by the Scherrer formula, were 9.33 nm (Pd-Co@HCS-(1)), 8.82 nm (Pd-Co@HCS-(2.8)), 7.29 nm (Pd-Co@HCS-(4.4)), and 8.94 nm (Pd-Co@HCS-(6.6)). As the mass ratio $\mathrm{m}_{\mathrm{Pd}} / \mathrm{m}_{\mathrm{Co}}$ increased from 1 to 4.4 , the Pd crystal sizes decreased 
from 9.33 to $7.29 \mathrm{~nm}$. The exposed active sites from Pd were increased when Co amount reduced (namely higher $\mathrm{m}_{\mathrm{Pd}} / \mathrm{m}_{\mathrm{Co}}$ value) since Co might have covered certain Pd active sites. When the $\mathrm{m}_{\mathrm{Pd}} / \mathrm{m}_{\mathrm{Co}}$ increased to 6.6, however, the crystal size increased to $8.94 \mathrm{~nm}$, which can be explained by fact that the agglomeration of the Pd nanoparticles occurred due to a small amount of Co being insignificantly dispersed in the Pd. Therefore, a proper ratio between $\mathrm{Pd}$ and $\mathrm{Co}$ (4.4:1) can provide more catalytic active sites from $\mathrm{Pd}$ and improve the dispersion of $\mathrm{Pd}$, simultaneously.
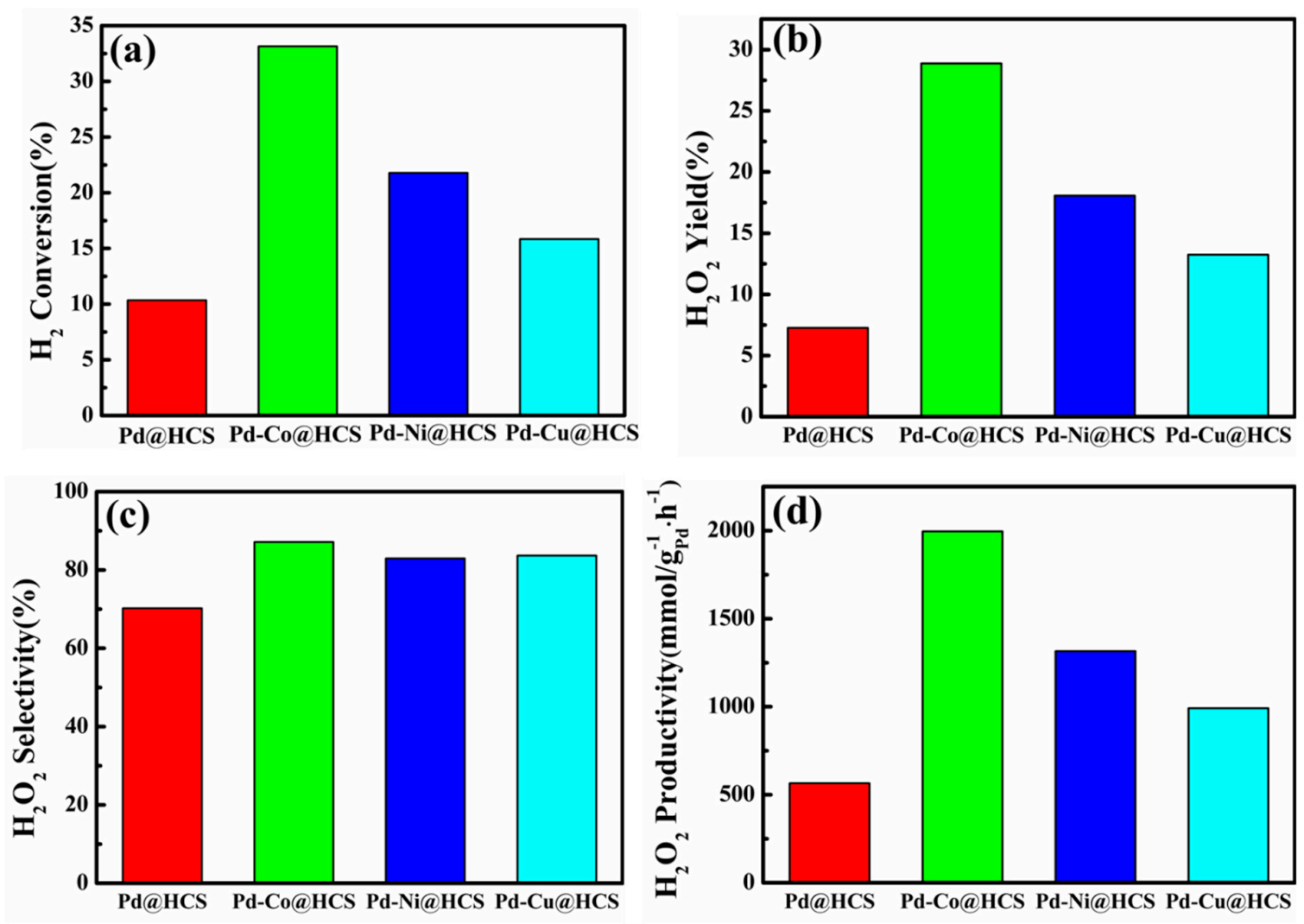

Figure 4. Catalytic activity of the prepared catalysts Pd@HCS and Pd-M@HCS. (a) $\mathrm{H}_{2}$ conversion, (b) $\mathrm{H}_{2} \mathrm{O}_{2}$ yield, (c) $\mathrm{H}_{2} \mathrm{O}_{2}$ selectivity, and (d) $\mathrm{H}_{2} \mathrm{O}_{2}$ productivity.

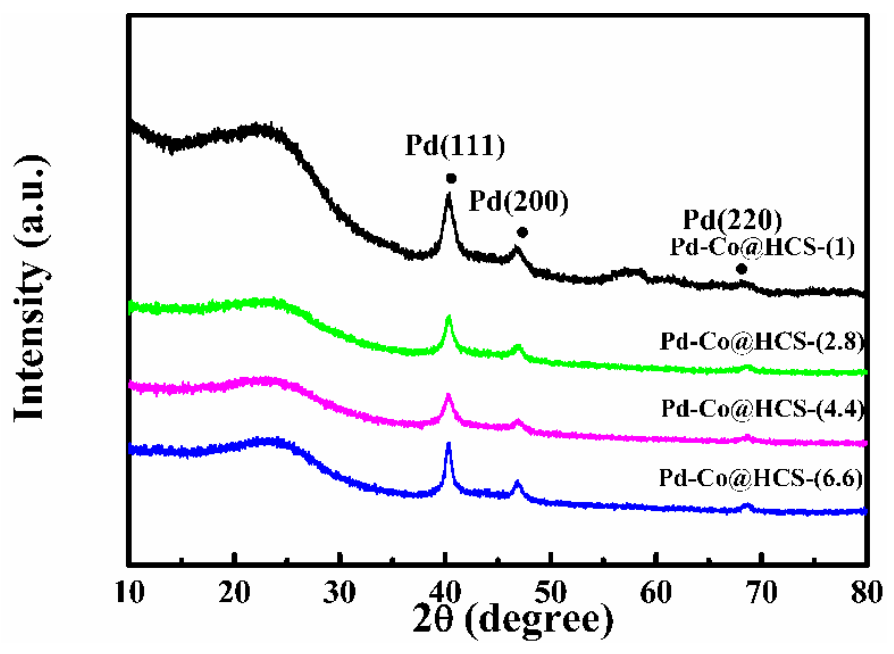

Figure 5. XRD patterns of Pd-Co@HCS-(X). 


\subsection{2. $\mathrm{N}_{2}$ Adsorption-Desorption of Pd-Co@HCS- $(\mathrm{X})$}

Figure 6 shows $\mathrm{N}_{2}$ adsorption-desorption isotherms and pore size distribution of Pd-Co@HCS. Similarly, all the synthesized catalysts presented a typical type II isotherm adsorption curve. The monolayer adsorption at low relative pressure range $\left(\mathrm{P} / \mathrm{P}_{0}<0.01\right)$ indicated that all the Pd-Co@HCS- $(\mathrm{X})$ samples contained micropores. The adsorbed $\mathrm{N}_{2}$ gradually increased with the increase of $\mathrm{P} / \mathrm{P}_{0}$, while it sharply increased when $\mathrm{P} / \mathrm{P}_{0}>0.9$, indicating that both micropores and macropores existed in Pd-Co@HCS-(X). Meanwhile, the hysteresis loops revealed that the Pd-Co@HCS- $(X)$ catalysts were mainly composed of mesopores. The PSD shown in Figure $6 \mathrm{~b}$ also illustrates that they had small numbers of micropores with pore sizes of 1-2 nm and large numbers of mesopores and macropores. The $S_{\mathrm{BET}}, \mathrm{V}_{\text {mic }}$ and $\mathrm{D}_{\text {pore }}$ are summarized in Table 2. As mentioned before, a higher specific surface area can enhance $\mathrm{H}_{2} \mathrm{O}_{2}$ selectivity by providing more adsorption sites for $\mathrm{H}_{2}$ and $\mathrm{O}_{2}$ molecules. Thus, Pd-Co@HCS-(4.4), with the highest $\mathrm{S}_{\mathrm{BET}}=683.36 \mathrm{~m}^{2} / \mathrm{g}$, probably has the best catalytic performance for DSHP.
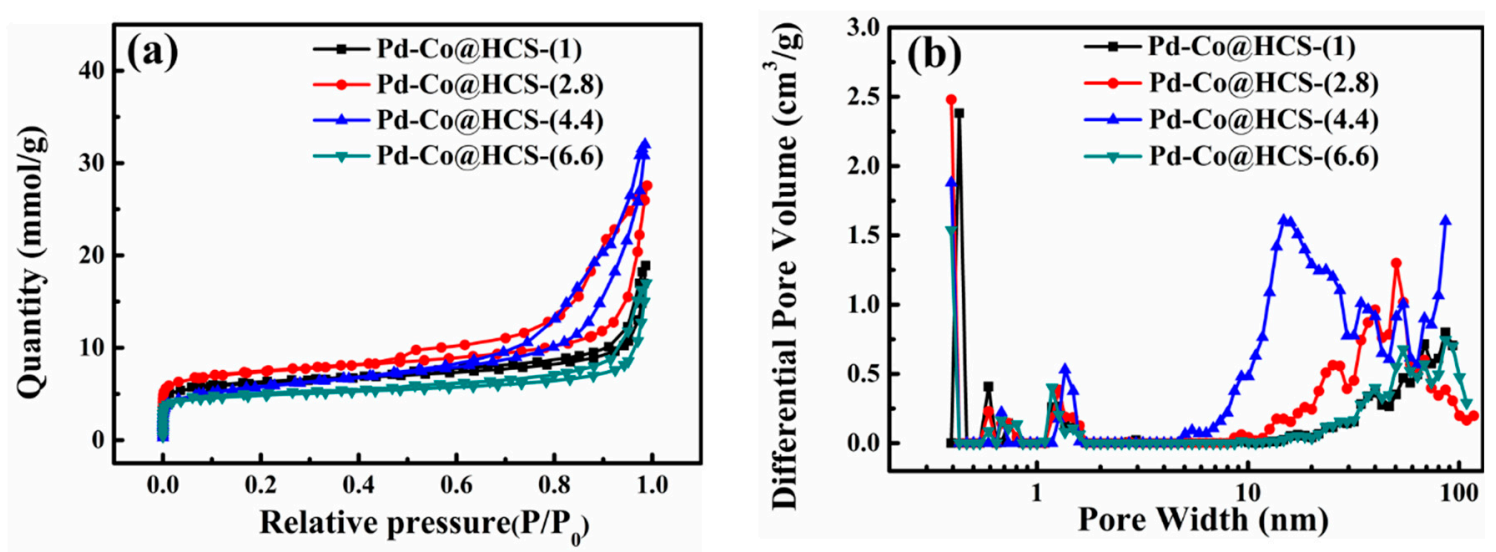

Figure 6. $\mathrm{N}_{2}$ adsorption-desorption of Pd@HCS-(X). (a) Isotherm adsorption line; (b) pore size distribution.

Table 2. Textural properties and Pd loading of Pd-Co@HCS-(X).

\begin{tabular}{ccccc}
\hline Catalysts & $\mathrm{S}_{\text {BET }}\left(\mathbf{m}^{\mathbf{2}} / \mathbf{g}\right)$ & $\mathbf{V}_{\text {mic }}\left(\mathbf{c m}^{\mathbf{3}} / \mathbf{g}\right)$ & $\mathbf{D}_{\text {pore }}(\mathbf{n m})$ & Pd Loading $(\mathbf{w t} \mathbf{\%})$ \\
\hline Pd-Co@HCS-(1) & 487.96 & 0.17 & 12.29 & 4.05 \\
Pd-Co@HCS-(2.8) & 601.61 & 0.19 & 9.97 & 4.05 \\
Pd-Co@HCS-(4.4) & 683.36 & 0.16 & 8.78 & 4.05 \\
Pd-Co@HCS-(6.6) & 400.03 & 0.13 & 14.99 & 4.05 \\
\hline
\end{tabular}

\subsubsection{Activity Test of Pd-Co@HCS-(X) for DSHP}

Figure 7 demonstrates the effect of the ratio of $\mathrm{m}_{\mathrm{Pd}} / \mathrm{m}_{\mathrm{Co}}$ on the catalytic performances for the direct synthesis of $\mathrm{H}_{2} \mathrm{O}_{2}$ from $\mathrm{H}_{2}$ and $\mathrm{O}_{2}$. As expected, Pd-Co@HCS-(4.4) had the largest surface area and provided the best $\mathrm{H}_{2} \mathrm{O}_{2}$ selectivity of $87 \%$ and $\mathrm{H}_{2} \mathrm{O}_{2}$ productivity of $1996 \mathrm{mmolg} \mathrm{Pd}^{-1} \cdot \mathrm{h}^{-1}$. 

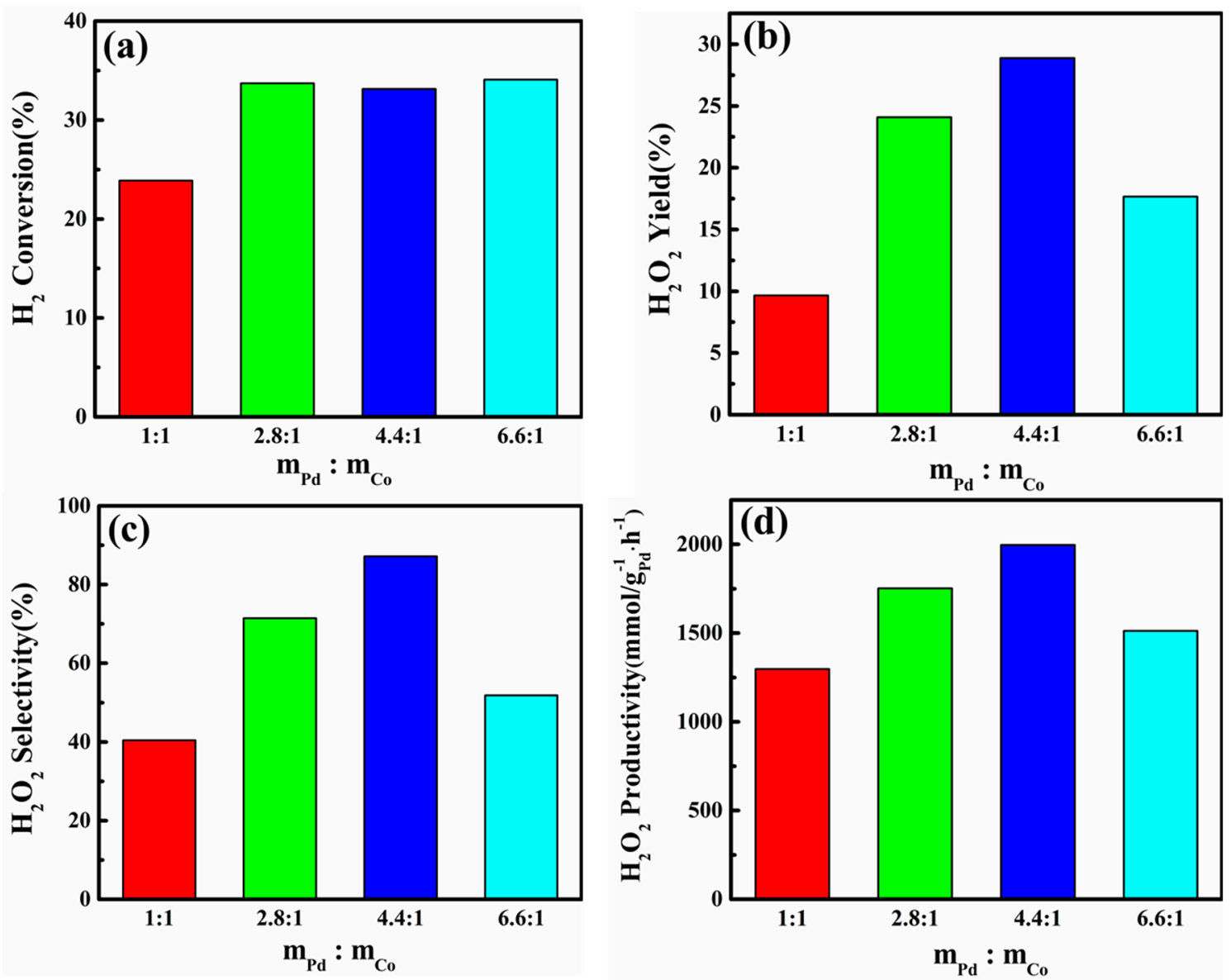

Figure 7. Catalytic activity of Pd-Co@HCS- $(X)\left(=1,2.8,4.4\right.$ and 6.6). (a) $\mathrm{H}_{2}$ conversion, $(\mathbf{b}) \mathrm{H}_{2} \mathrm{O}_{2}$ yield, (c) $\mathrm{H}_{2} \mathrm{O}_{2}$ selectivity, and (d) $\mathrm{H}_{2} \mathrm{O}_{2}$ productivity.

\section{Experimental}

\subsection{Materials}

Chloropalladic acid $\left(\mathrm{H}_{2} \mathrm{PdCl}_{4}, \mathrm{AR}\right)$ was purchased from Sigma-Aldrich (Shanghai, China). Cobalt (II) nitrate hexahydrate $\left(\mathrm{Co}\left(\mathrm{NO}_{3}\right)_{2} \cdot 6 \mathrm{H}_{2} \mathrm{O}, \mathrm{AR}\right)$, nickel chloride $\left(\mathrm{NiCl}_{2} \cdot 6 \mathrm{H}_{2} \mathrm{O}, \mathrm{AR}\right)$, copper chloride $\left(\mathrm{CuCl}_{2} \cdot 2 \mathrm{H}_{2} \mathrm{O}\right)$, hydrofluoric acid $(\mathrm{HF}, 40 \%, \mathrm{AR})$, and sodium borohydride $\left(\mathrm{NaBH}_{4}, 96 \%, \mathrm{AR}\right)$ were purchased from Sinopharm Chemical Reagent Co. (Shanghai, China). Cyclohexane, $n$-octanol, absolute ethanol (99.7\%, AR) and methanol (99.5\%, AR) were purchased from Tianjin Fuyu Fine Chemical Co. (Shanghai, China). Tetraethyl orthosilicate (TEOS, 9.0\%, AR) was purchased from Aladdin (Shanghai, China). Cetyltrimethylammonium bromide (CTAB, 99.0\%, AR) and Brij56 were purchased from Tokyo Chemical Industry (Shanghai, China). Ethylene glycol (AR), ammonia solution ( $25 \%-28 \%$, AR), resorcinol $(99.5 \%, \mathrm{AR})$, and $\mathrm{H}_{2} \mathrm{O}_{2}(30 \%, \mathrm{AR})$ were purchased from Chengdu Jinshan Chemical Reagent Co., Ltd. (Shanghai, China). Sulfuric acid $\left(\mathrm{H}_{2} \mathrm{SO}_{4}, 98 \%\right.$, AR) was purchased from Tianjin Chemical Reagent Factory Kaida Chemical Factory (Shanghai, China). Formaldehyde (37.0\%-40.0\%, AR) was purchased from Xilong Science Co., Ltd (Shanghai, China).

\subsection{Catalyst Preparation}

Zero-point-zero-eight grams of CTAB were dissolved in $10 \mathrm{~mL}$ of ethylene glycol and then mixed with a $0.075 \mathrm{M}$ precursor aqueous solution $\left(\mathrm{H}_{2} \mathrm{PdCl}_{4}, \mathrm{Co}\left(\mathrm{NO}_{3}\right)_{2} \cdot 6 \mathrm{H}_{2} \mathrm{O}, \mathrm{NiCl}_{2} \cdot 6 \mathrm{H}_{2} \mathrm{O}\right.$ and $\left.\mathrm{CuCl}_{2} \cdot 2 \mathrm{H}_{2} \mathrm{O}\right)$. The $\mathrm{pH}$ was adjusted to 10 by adding an ammonia aqueous solution. The Pd-M seed solutions were then formed after reacting for $2 \mathrm{~h}$. 
Eight-point-seven-two grams of the Brij56 surfactant were added into a mixed solution of $40 \mathrm{~mL}$ of cyclohexane and $10 \mathrm{~mL}$ of $n$-octanol at $35^{\circ} \mathrm{C}$ with magnetic stirring to a form homogeneous solution. Afterward, the Pd-M seed solution was added and stirred for $2 \mathrm{~h}$. Then, $450 \mu \mathrm{L}$ of a $10 \mathrm{wt} . \% \mathrm{NaBH}_{4}$ solution was dropped in (the color of the solution changed to black), and after $30 \mathrm{~min}, 2 \mathrm{~mL}$ of an ammonia aqueous solution was added into to the black solution. Two milliliters of TEOS was added after $1 \mathrm{~h}$, and the hydrolytic condensation reaction of the silica precursor was proceeded for $6 \mathrm{~h}$. Afterward, the microemulsion was damaged by adding $50 \mathrm{~mL}$ of ethanol. Finally, $\mathrm{Pd}-\mathrm{M} @ \mathrm{SiO}_{2}$ was obtained by centrifugation and was washed with ethanol three times.

The as-obtained $\mathrm{Pd} @ \mathrm{SiO}_{2}$ was dispersed in a mixed solution of $70 \mathrm{~mL}$ of deionized water and $30 \mathrm{~mL}$ of ethanol by ultrasonication, followed by the addition of $4 \mathrm{~g}$ of CTAB with magnetic stirring at $35^{\circ} \mathrm{C}$ for $30 \mathrm{~min} ; 0.35 \mathrm{~g}$ resorcinol was then added to the solution. After the resorcinol was dissolved, $0.5 \mathrm{~mL}$ of formaldehyde and $0.2 \mathrm{~mL}$ of an ammonia solution were added to the solution under stirring and then stirred for $6 \mathrm{~h}$ to form a uniform dispersion. The mixture was centrifugated and washed with ethanol three times. Afterward, the product Pd-M@SiO${ }_{2} @ \mathrm{RF}$ was collected after being dried at $50{ }^{\circ} \mathrm{C}$ for overnight.

The obtained Pd-M@SiO $@$ RF was pyrolyzed at $600{ }^{\circ} \mathrm{C}$ for $2 \mathrm{~h}$ under an $\mathrm{N}_{2}$ atmosphere to remove CTAB and to form Pd-M@SiO ${ }_{2} @ \mathrm{C}$. Next, Pd-M@SiO ${ }_{2} @ \mathrm{C}$ was dispersed in $36 \mathrm{~mL}$ of deionized water, and then the mixture was etched by adding $5 \mathrm{~mL}$ of an $\mathrm{HF}$ solution. After being stirred for $12 \mathrm{~h}$, the product was centrifugated and washed by DI water 3 times and then dried at $80^{\circ} \mathrm{C}$ overnight to obtain Pd-M@HCS. Finally, the catalyst for DSHP was collected by calcined under air for $2 \mathrm{~h}$ and then reduced at $250^{\circ} \mathrm{C}$ under $\mathrm{H}_{2}$ for $2.5 \mathrm{~h}$. The prepared Pd-Co@HCS with different mass ratios of $\mathrm{m}_{\mathrm{Pd}}: \mathrm{m}_{\mathrm{Co}}$ $=1: 1,2.8: 1,4.4: 1$ and 6.6:1 were referred as Pd-Co@HCS-(1), Pd-Co@HCS-(2.8), Pd-Co@HCS-(4.4) and Pd-Co@HCS-(6.6), respectively.

\subsection{Catalyst Characterization}

The morphology, size, and elemental composition of the catalyst were determined by a Tecnai G2 F20 S-Twin TEM (transmission electron microscope) that was equipped with an energy-dispersive X-ray (EDX) spectroscopic analyzer (city, State Abbr. (if has), country) and operated at a voltage of $200 \mathrm{kV}$. The XRD patterns were obtained by using a D8 Advance diffractometer (city, State Abbr. (if has), country) that operated at $40 \mathrm{kV}$ and $40 \mathrm{~mA}$ with $\mathrm{Cu} \mathrm{K} \alpha$ radiation $(\lambda=1.5418 \AA)$. The surface areas and pore structures were measured by using an ASAP $2020 \mathrm{M}$ analyzer (Micromeritics Co.) at $77 \mathrm{~K}$.

\subsection{Activity Test}

The catalytic performance of the catalysts for the DSHP reaction was tested for $1 \mathrm{~h}$ in a jacketed glass reactor at $0{ }^{\circ} \mathrm{C}$ and $0.1 \mathrm{MPa}$. A mixed solution of $80 \mathrm{~mL}$ of methanol $(99.7 \%)$ and $0.9 \mathrm{~mL}$ of $\mathrm{H}_{2} \mathrm{SO}_{4}(98 \%)$ was used as the reaction medium. The total flow rate of the reactants was kept at $16 \mathrm{~mL} / \mathrm{min}$, including $2 \mathrm{~mL} / \mathrm{min}_{2}, 4 \mathrm{~mL} / \mathrm{min}_{2}$, and $10 \mathrm{~mL} / \mathrm{min}_{2}$. The concentration of the generated $\mathrm{H}_{2} \mathrm{O}_{2}$ and remaining $\mathrm{H}_{2}$ were detected by iodometric titration and gas chromatography, respectively. $\mathrm{H}_{2}$ conversion, $\mathrm{H}_{2} \mathrm{O}_{2}$ selectivity, $\mathrm{H}_{2} \mathrm{O}_{2}$ yield, and $\mathrm{H}_{2} \mathrm{O}_{2}$ productivity were calculated by the following equations:

$$
\begin{gathered}
\mathrm{H}_{2} \text { conversion }(\%)=\frac{\text { moles of } \mathrm{H}_{2} \text { reacted }}{\text { moles of } \mathrm{H}_{2} \text { fed }} \times 100 \\
\mathrm{H}_{2} \mathrm{O}_{2} \text { yield }(\%)=\frac{\text { moles of } \mathrm{H}_{2} \mathrm{O}_{2} \text { formed }}{\text { moles of } \mathrm{H}_{2} \text { fed }} \times 100 \\
\mathrm{H}_{2} \mathrm{O}_{2} \text { selectivity }(\%)=\frac{\text { moles of } \mathrm{H}_{2} \mathrm{O}_{2} \text { formed }}{\text { moles of } \mathrm{H}_{2} \text { reacted }} \times 100 \\
\mathrm{H}_{2} \mathrm{O}_{2} \text { productivity }\left(\text { mmol g }{ }_{P d}{ }^{-1} \cdot \mathrm{h}^{-1}\right)=\frac{\text { moles of } \mathrm{H}_{2} \mathrm{O}_{2} \text { formed }}{\text { mass of Pd fed } \times \text { time }}
\end{gathered}
$$




\section{Conclusions}

The yolk-shell structure nanocatalyst Pd-M@HCS $(\mathrm{M}=\mathrm{Co}, \mathrm{Ni}, \mathrm{Cu})$ with bimetal nanoparticles as its core and porous carbon as its shell layer was successfully synthesized by reverse micelle and self-assembly methods. The incorporated $\mathrm{M}$ components enhanced $\mathrm{H}_{2} \mathrm{O}_{2}$ selectivity and $\mathrm{H}_{2} \mathrm{O}_{2}$ productivity by reducing the Pd nanoparticle crystal size and forming more active sites. Pd-Co@HCS provided the best catalytic performances for DSHP with an $\mathrm{H}_{2}$ conversion of $33 \%$, an $\mathrm{H}_{2} \mathrm{O}_{2}$ yield of $29 \%$, an $\mathrm{H}_{2} \mathrm{O}_{2}$ selectivity of $87 \%$, and an $\mathrm{H}_{2} \mathrm{O}_{2}$ productivity of $1996 \mathrm{mmolg} \mathrm{Pd}^{-1} \cdot \mathrm{h}^{-1}$, and these were increased by 230\%,314\%, 24\%, and 253\%, respectively, compared to Pd@HCS. Furthermore, the effect of Co content in the Pd-Co on the catalytic activities was investigated. It was found that the catalyst showed the best performance when the ratio $\mathrm{m}_{\mathrm{Pd}}: \mathrm{m}_{\mathrm{Co}}$ was 4.4:1. This was because when the mass ratio $\mathrm{m}_{\mathrm{Pd}} / \mathrm{m}_{\mathrm{Co}}$ increased from 1 to 4.4 , the Pd crystal sizes decreased from 9.33 to $7.29 \mathrm{~nm}$. Meanwhile, the more Pd active sites were exposed when $\mathrm{m}_{\mathrm{Pd}} / \mathrm{m}_{\mathrm{Co}}=4.4$. However, when the $\mathrm{m}_{\mathrm{Pd}} / \mathrm{m}_{\mathrm{Co}}$ increased to 6.6, the crystal size increased to $8.94 \mathrm{~nm}$ because of the agglomeration of the Pd nanoparticles. Therefore, a proper mass ratio between $\mathrm{Pd}$ and $\mathrm{Co}$ can provide more efficient catalytic activity. What is more, the yolk-shell structure nanocatalyst Pd-M@HCS $(\mathrm{M}=\mathrm{Co}, \mathrm{Ni}, \mathrm{Cu})$ with bimetal nanoparticles as its core and porous carbon as its shell layer can also be applied to electrocatalysis [22,23].

Author Contributions: Conceptualization, H.P. and Q.L.; Data curation, Y.W.; Formal analysis, Y.W.; Funding acquisition, Q.L.; Investigation, Y.W.; Methodology, Y.W., Y.S. and J.Z.; Project administration, Q.L.; Resources, Q.L.; Supervision, H.P. and Q.L.; Writing-original draft, Y.W.; Writing-review \& editing, Q.L. All authors have read and agreed to the published version of the manuscript.

Funding: This research was funded by the Natural Science Foundation of China (Grant 21366008), the Science and Technology Foundation of Guizhou Province (Grant (2014), 2008; (2017) 7254), the Natural Science Foundation of China (Grant 21666007), and the Science and Technology Support Plan Projects of Guizhou Province (Grant (2018) 2192). And the APC was funded by the Science and Technology Support Plan Projects of Guizhou Province (Grant (2018) 2192).

Conflicts of Interest: The contents of this manuscript have not been copyrighted or published previously. The contents of this manuscript are not now under consideration for publication elsewhere. There are no directly related manuscripts or abstracts, published or unpublished, by any authors of this manuscript. The authors declare no competing financial interest.

\section{References}

1. Edwards, J.K.; Freakley, S.J.; Carley, A.F.; Kiely, C.J.; Hutchings, G.J. Strategies for designing supported gold-palladium bimetallic catalysts for the direct synthesis of hydrogen peroxide. Acc. Chem. Res. 2014, 47, 845-854. [CrossRef] [PubMed]

2. Hage, R.; Lienke, A. Applications of transition-metal catalysts to textile and wood-pulp bleaching. Angew. Chem. Int. Ed. 2005, 45, 206-222. [CrossRef] [PubMed]

3. Ju, Y.P.; Lee, I.H. Decomposition of acetic acid by advanced oxidation processes. Korean J. Chem. Eng. 2009, 26, 387-391.

4. Kim, H.; Lee, W.; Ahn, C.; Kim, B.; Kim, J.; Oh, H. Kinetic correlation between degradation and dechlorination of perchloroethylene in the Fenton reaction. Korean J. Chem. Eng. 2010, 27, 1750-1754. [CrossRef]

5. Choi, S.S.; Sang, H.S.; Kang, D.G.; Ha, J.H.; Cha, H.J. Removal of neurotoxic ethyl parathion pesticide by two-stage chemical/enzymatic treatment system using Fenton's reagent and organophosphorous hydrolase. Korean J. Chem. Eng. 2010, 27, 900-904. [CrossRef]

6. Campos-Martin, J.M.; Blanco-Brieva, G.; Fierro, J.L.G. Hydrogen peroxide synthesis:an outlook beyond the anthraquinone process. Angew. Chem. Int. Ed. 2006, 45, 6962-6984. [CrossRef] [PubMed]

7. Ranganathan, S.; Sieber, V. Recent Advances in the Direct Synthesis of Hydrogen Peroxide Using Chemical Catalysis-A Review. Catalysts 2018, 8. [CrossRef]

8. Samanta, C. Direct synthesis of hydrogen peroxide from hydrogen and oxygen: An overview of recent developments in the process. Appl. Catal. A Gen. 2008, 350, 133-149. [CrossRef]

9. Lewis, R.J.; Hutchings, G.J. Recent Advances in the Direct Synthesis of $\mathrm{H}_{2} \mathrm{O}_{2}$. ChemCatChem 2019, 11, $298-308$. [CrossRef] 
10. Guo, Q.; Liu, D.; Zhang, X.; Li, L.; Hou, H.; Niwa, O.; You, T. Pd-Ni Alloy Nanoparticle/Carbon Nanofiber Composites: Preparation, Structure, and Superior Electrocatalytic Properties for Sugar Analysis. Anal. Chem. 2014, 86, 5898-5905. [CrossRef]

11. Feng, L.; Chong, H.; Li, P.; Xiang, J.; Fu, F.; Yang, S.; Yu, H.; Sheng, H.; Zhu, M. Pd-Ni Alloy Nanoparticles as Effective Catalysts for Miyaura-Heck Coupling Reactions. J. Phys. Chem. C 2015, 119, 11511-11515. [CrossRef]

12. Solsona, B.E.; Edwards, J.K.; Landon, P.; Carley, A.F.; Herzing, A.; Kiely, C.J.; Hutchings, G.J. Direct Synthesis of Hydrogen Peroxide from $\mathrm{H}_{2}$ and $\mathrm{O}_{2}$ Using $\mathrm{Al}_{2} \mathrm{O}_{3}$ Supported Au-Pd Catalysts. Chem. Mater. 2006, 18, 2689-2695. [CrossRef]

13. Freakley Simon, J.; He, Q.; Harrhy Jonathan, H.; Lu, L.; Crole David, A.; Morgan David, J.; Ntainjua Edwin, N.; Edwards Jennifer, K.; Carley Albert, F.; Borisevich Albina, Y.; et al. Palladium-tin catalysts for the direct synthesis of $\mathrm{H}_{2} \mathrm{O}_{2}$ with high selectivity. Science 2016, 351, 965-968. [CrossRef] [PubMed]

14. Paunovic, V.; Ordomsky, V.; D’Angelo, M.F.N.; Schouten, J.C.; Nijhuis, T.A. Direct synthesis of hydrogen peroxide over Au-Pd catalyst in a wall-coated microchannel. J. Catal. 2014, 309, 325-332. [CrossRef]

15. Lu, A.H.; Spliethoff, B.; Schüth, F. Aqueous Synthesis of Ordered Mesoporous Carbon via Self-Assembly Catalyzed by Amino Acid. Chem. Mater. 2008, 20, 5314-5319. [CrossRef]

16. Yokoi, T.; Sakamoto, Y.; Terasaki, O.; Kubota, Y.; Okubo, T.; Tatsumi, T. Periodic Arrangement of Silica Nanospheres Assisted by Amino Acids. J. Am. Chem. Soc. 2006, 128, 13664-13665. [CrossRef]

17. Liu, J.; Qiao, S.Z.; Liu, H.; Chen, J.; Orpe, A.; Zhao, D.; Lu, G.Q. Extension of The Stöber Method to the Preparation of Monodisperse Resorcinol-Formaldehyde Resin Polymer and Carbon Spheres. Angew. Chem. 2011, 50, 5947-5951. [CrossRef]

18. Liu, P.; Lin, Q.; Pan, H.; Zhao, J.; Zhao, C.; Wang, Y. Direct synthesis of hydrogen peroxide from hydrogen and oxygen over yolk-shell nanocatalyst Pd@HCS with controlled Pd nanoparticle size. J. Catal. 2019, 377, 511-523. [CrossRef]

19. Liu, Z.; Qi, J.; Liu, M.; Zhang, S.; Fan, Q.; Liu, H.; Liu, H.; Liu, K.; Zheng, H.; Yin, Y.; et al. Aqueous Synthesis of Ultrathin Platinum/Non-Noble Metal Alloy Nanowires for Enhanced Hydrogen Evolution Activity. Angew. Chem. 2018. [CrossRef]

20. Vondrova, M.; Klimczuk, T.; Miller, V.L.; Kirby, B.W.; Yao, N.; Cava, R.J.; Bocarsly, A.B. Supported Superparamagnetic Pd/Co Alloy Nanoparticles Prepared from a Silica/Cyanogel Co-gel. Chem. Mater. 2005, 17, 6216-6218. [CrossRef]

21. Ma, J.; Xu, L.; Xu, L.; Wang, H.; Xu, S.; Li, H.; Xie, S.; Li, H. Highly Dispersed Pd on Co-B Amorphous Alloy: Facile Synthesis via Galvanic Replacement Reaction and Synergetic Effect between Pd and Co. Am. Chem. Soc. 2013, 3, 985-992. [CrossRef]

22. Liu, D.; Guo, Q.; Hou, H.; Niwa, O.; You, T. PdxCoy Nanoparticle/Carbon Nanofiber Composites with Enhanced Electrocatalytic Properties. ACS Catal. 2014, 4, 1825-1829. [CrossRef]

23. Bai, Z.; Xu, P.; Chao, S.; Yan, H.; Cui, Q.; Niu, L.; Yang, L.; Qian, J. A facile one-step preparation of a Pd-Co bimetallic hollow nanosphere electrocatalyst for ethanol oxidation. Catal. Sci. Technol. 2013, 3, 2843-2848. [CrossRef]

(C) 2020 by the authors. Licensee MDPI, Basel, Switzerland. This article is an open access article distributed under the terms and conditions of the Creative Commons Attribution (CC BY) license (http://creativecommons.org/licenses/by/4.0/). 